MATEC Web of Conferences 2, 03001 (2012)

DOI: $10.1051 /$ matecconf $/ 20120203001$

C Owned by the authors, published by EDP Sciences, 2012

\title{
Application of Cold Formed Steel Framing Structures for Construction in Zones Affected by Land Subsidence
}

\author{
J.-A. Ortiz ${ }^{1}$, J. Pacheco ${ }^{1}$, M.-E. Zermeño ${ }^{1}$, F.-A. Alonso $^{2}$, J.-J. Soto ${ }^{3}$, M.-R. Moreno ${ }^{3}$, L.-O. Correa ${ }^{4}$ \\ ${ }^{1}$ Universidad Autonoma de Aguascalientes, Department of Construction and Structures, \\ Aguascalientes, Mexico \\ ${ }^{2}$ Universidad Autónoma de Chiapas, Engineering School, Chiapas, Mexico \\ ${ }^{3}$ Instituto Tecnologico Aguascalientes, Department Electric and Electronic Engineering, \\ Aguascalientes, Mexico \\ ${ }^{4}$ Universidad Politecnica de Aguascalientes, Department of Mechanical Engineering, \\ Aguascalientes, Mexico
}

\begin{abstract}
The main objective of this research project is to study the application of structural systems based on light gauge cold-formed steel framing to housing in subsidence zones, having the following scopes: characterize the typical settlements in a discontinuity due to subsidence, to build a laboratory facility to simulate these settlements, to simulate and to evaluate numerically and in laboratory in a full scale model the structural performance of a house subjected to settlements due to subsidence, in terms of its stresses and strains and, eventually, its capacity of retrieval to its nondeformed shape.
\end{abstract}

\section{Introduction}

\subsection{Land subsidence}

Land subsidence subsidence due to groundwater withdrawal is widespread in the Mexican territory in recent decades in valleys where the aquifer consists of unconsolidated material such as alluvial, lacustrine, or volcano-sedimentary deposits geologically recent [1-6]. When the aquifer bedrock is irregular, the land subsidence causes faults and fractures on the surface granular fills damaging the existing urban infrastructure [7, 8, 3]. Ground fracturing associated with land subsidence has been widely studied in several places in the world [9-11]. In Mexico, the phenomenon is not unknown, especially in floodplain areas in central Mexico, such as Celaya, Silao, Queretaro, San Luis Potosi, Morelia, Mexico City, etc., where some problems related with subsidence and fractures associated with overuse of granular aquifer were reported.

\subsection{Land subsidence effects on buildings}

Active fracture zones associated with land subsidence, induce displacements in buildings in the form of differential settlement, causing damages to structural systems in houses, which in Mexico are 
mostly built with masonry, which are particularly designed to transfer loads in compressive, shear and plane flexure way, through walls to a foundation system. The most widely used systems are confined masonry walls with reinforced concrete beams and columns and also internal reinforced masonry wall, which both met the requirements for structural masonry located in seismic zones. However, the problem of land subsidence subsidence induced structural deformations of a different nature to the problems caused by dynamic lateral loads.

\subsection{Light gauge steel framing construction}

Cold formed steel is a type of steel with thickness of its cross section of the order of a few millimetres. Some of the most common sections that are managed commercially are shown in "Figure 1". However, the advantage of this type of material is that can produce non-standard sections and unusual geometries, which, being very light, are able to perform structurally very efficiently for many applications, including construction of housing.
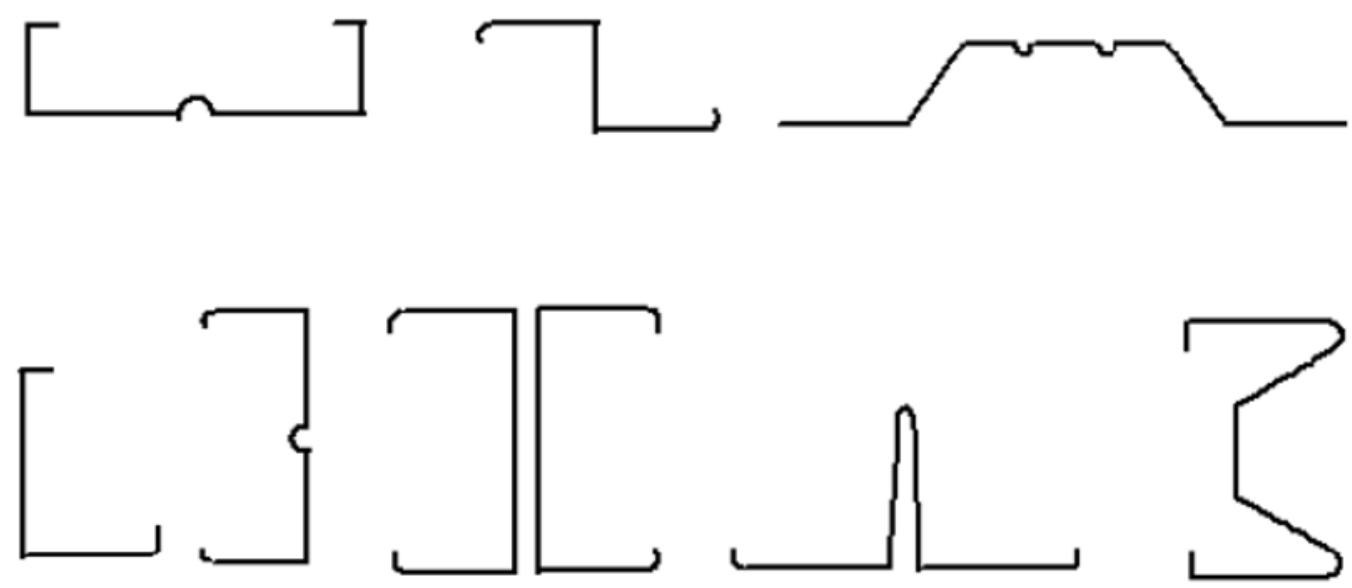

Fig. 1. Typical light steel framing cross sections

The advantages of building with cold formed steel in areas affected by land subsidence are that this system has an extremely favorable mechanical behavior from the standpoint of ductility, making it ideal for absorbing significant deformations without significant damages. Also, the versatility and practicality of this method of construction, allows to repair quickly and easily any structural element of the affected building.

\subsection{General objective}

The main objective of this project is to analyze the technical feasibility of applying the constructivestructural systems based on cold formed steel (light gauge steel framing - LGSF) for housing in areas affected by ground cracking associated with the phenomenon of land subsidence. This means meeting the following objectives:

- To define the characteristic ground settlements that are generated at the edges of a crack in the ground due to land subsidence.

- To build and implement an experimental device capable of simulating in laboratory these settlements.

- To simulate numerically using advanced structural analysis software the structural behavior of a model house LGSF under differential settlements due to land subsidence. 
- To simulate in laboratory the structural behavior (scale 1:1) of a housing structure, with differential settlements caused by land subsidence.

- To assess the structural behavior in terms of the magnitude of stresses and strains suffered and the ability of the structure to return to its non-deformed configuration.

\section{Experimental methodology}

\subsection{Structural materials}

The steel sheet used to manufacture the structural elements is hot rolled with a yield strength of 33 ksi (ASTM A 653). The methodology used in this research project consisted basically in four experimental stages. It is noteworthy that the project is still in process, we are working specifically on Stage 3.

\subsection{Stage 1. Fabrication of structural elements}

- To design and to detail the structural elements, so they can be reproduced as many times as necessary without any variations in their dimensions.

- To fabricate structural elements ensuring that stresses during the manufacturing process are smaller than the maximum allowable in the process of structural design.

\subsection{Stage 2. Structural analysis and design of prototype house}

- To design and propose the most appropriate structural elements of cold formed steel (LGSF) for a prototype house.

- To detail the connections of structural elements of the LGSF prototype house.

- To perform experimental studies of some of the structural elements and connections to verify the real response of the elements.

- To compose a calculation document that contains the performance of prototype house before gravitational and lateral loads.

\subsection{Stage 3. Design and construction of the device to simulate ground settlements}

- To design and to build a platform or a device for laboratory simulation of differential settlements as observed in reality by land subsidence.

\subsection{Stage 4. Construction of prototype house and structural experimentation}

- To erect and assemble the house prototype.

- To submit the house prototype to conditions of stresses and strains caused by differential settlements similar to those observed by land subsidence.

- Prototype instrumentation to record the displacements and strains presented.

- Analysis and comparison of experimental results with the expected results related to numerical models, in terms of stresses and strains.

\section{Results}

As mentioned above, this research project is still in process, so that the results presented are partial. 


\section{MATEC Web of Conferences}

\subsection{Stage 1. Fabrication of structural elements}

The manufacturing process consists in passing the steel sheet by a rolling machine, the number and design of the rollers are made exclusively according to the profile to make. During the manufacturing process the steel sheet is subjected to different processes of forming and extension of its surface, so that may be affected by stresses that would weaken some parts of its cross section.

To obtain a good result in the manufacture of the profiles is highly desirable to have a mathematical simulation model of finite elements to know the deformations to which is undergoing steel sheet in order to limit maximum strain imposed on the material.

In this work we used a program called COPRA $®$, which is a software capable of calculate step by step the maximum strains to which is undergoing the steel sheet to obtain the final profile. "Figure 2" through "Figure 5" are presented some results obtained with this software for the manufacture of the profiles.

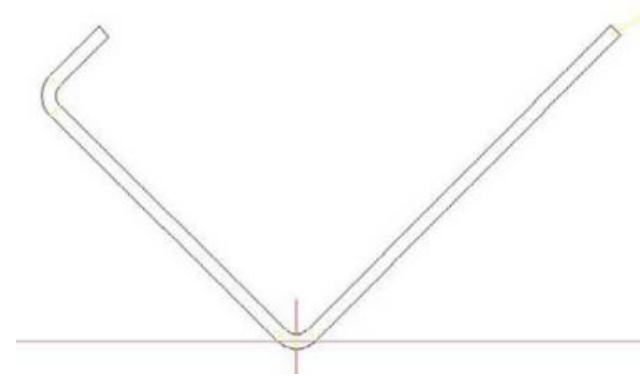

Fig. 2. Cross section of angle

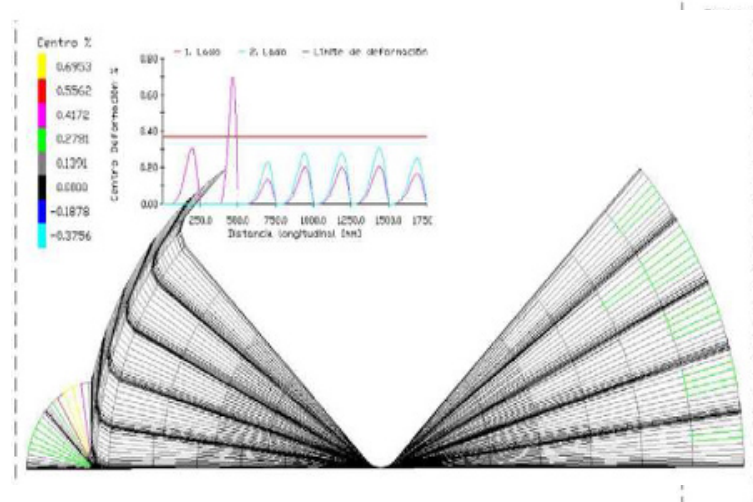

Fig. 4. "Flower" design with maximum strains by stages
Fig. 3. "Flower" design to obtain the final profile (number of folds)

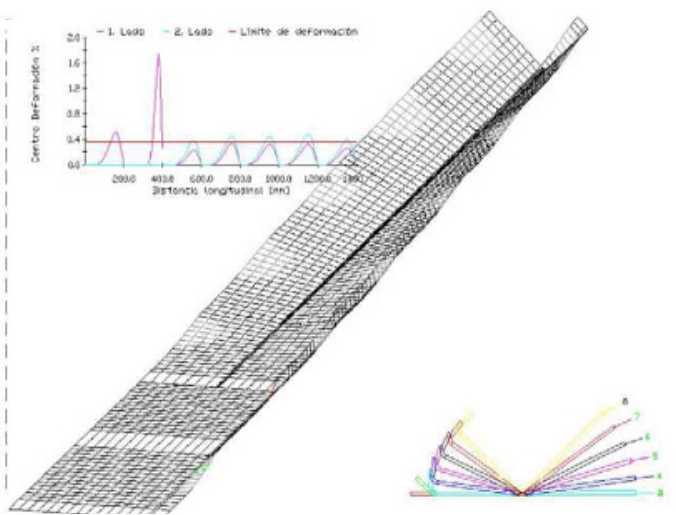

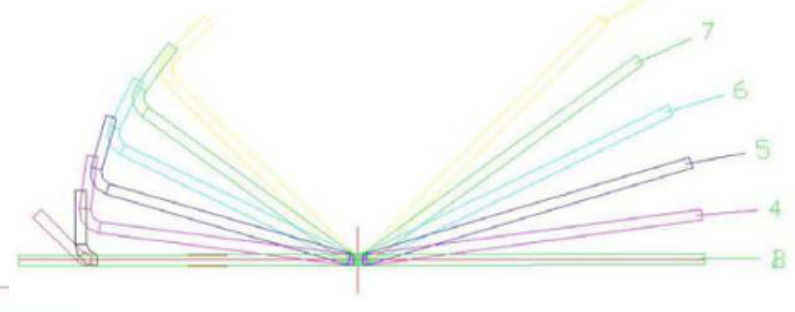

Fig. 5. Maximum strains in the extreme values of profile

\subsection{Stage 2. Structural analysis and design of prototype house}

For purposes of structural design and laboratory testing a 1:1 scale prototype, we chose a one story house corresponding to a prototype of the Housing Institute of the State of Aguascalientes (IVEA), Mexico, which is normally structured based in internally reinforced masonry walls of concrete blocks and roof slab system based on reinforced concrete beams and slabs. 


\subsection{Stage 2. Structural analysis and design of prototype house}

For purposes of structural design and laboratory testing a 1:1 scale prototype, we chose a one story house corresponding to a prototype of the Housing Institute of the State of Aguascalientes (IVEA), Mexico, which is normally structured based in internally reinforced masonry walls of concrete blocks and roof slab system based on reinforced concrete beams and slabs.

\subsection{Structural analysis}

In the process of structuring the house the criteria and construction techniques for this type of construction (LGSF) were considered [12,13]. To carry out the structural analysis of the house, we used commercial software, making a linear 3D analysis of first order, that is to say, considering proportionality between stresses and strains, the principle of superposition of actions and a geometrically linear behavior of materials and structure, taking into account combinations of gravitational loads (permanents and variables) and accidental loads (wind and quake).

By this analysis we obtained internal forces of structural members, which were compared with the maximum allowable strength capacities for each profile based on the type of demand to which they are subjected (compression, tension, bending, compression and bending, shear, torsion and / or combination of all).

\subsection{Structural Design}

The process of structural design of the house prototype consists in designing the cold formed steel structural profiles according to AISI 2007 Edition: North American Specification for the Design of Cold-Formed Steel Structural Members and Commentary on the Specification the AISI (American Iron and Steel Institute) - [14], determining the stresses and strains, and stability, according to the principles of rational mechanics and strength of materials, using a linear first-order analysis. It is of significant importance in the design of these elements, the consideration of local, distortional and lateral-torsional buckling.

\subsection{Stage 3. Design and construction of the device to simulate ground settlements}

This stage consists in design and build a platform or a device for laboratory simulation of differential settlements as observed in reality by land subsidence. In this sense, there is already a step forward in the conceptual design of this platform, which is shown in "Figure 6". Basically, the platform consists of 18 sub-platforms that may have a vertical scroll independently of each other, so it is possible to simulate the characteristics of ground settlement due to land subsidence, and it may represent various configurations of faulting.

\section{Conclusions}

Cold formed steel is a very interesting alternative for housing construction, since it presents several advantages over other traditional construction materials, however, it is necessary to consider many additional factors in the process of structural analysis and design, since it is a formed thin sheet material is more likely to be affected by the effects of buckling in its section.

Also, the manufacturing process of cold formed steel is a critical factor for the structural behavior, because during the bending and forming of the section, it may induce strains and stresses that can reduce the strength and capacity of the section.

On the other hand, once attained the objectives of this research project, will be possible to give a satisfactory response to the problem of damaged housing due to differential settlement caused by 
land subsidence, since mechanical properties of steel, will "absorb" properly the strains provoked without suffering major damage in its structure.

Likewise, the possibility of carrying out repairs in a simple and quick way, in houses based on light gauge steel framing which were damaged by land subsidence.

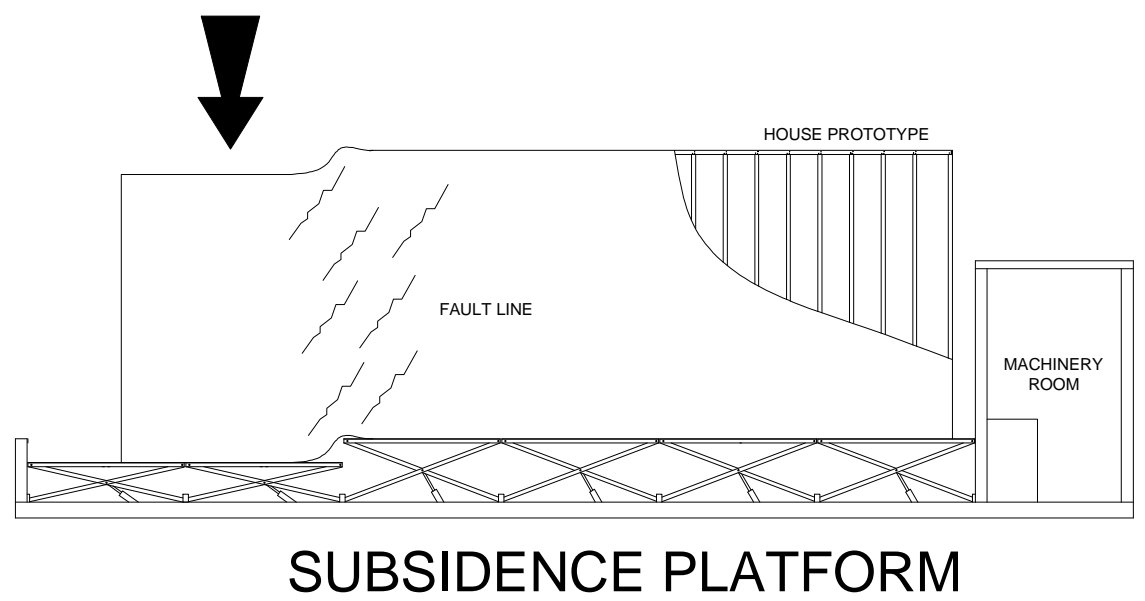

Fig. 6. Conceptual design of subsidence simulating platform

\section{References}

1. Figueroa, G., Case history 9.8: México D.F., México: Guidebook to studies of land subsidence due to ground-water withdrawal, prepared for the International Hydrological Programme, Working Group 8.4, Joseph F. Poland Chairman and Editor, pp. 217-232 (1984).

2. Aguirre, G.J., Zúñiga, R., Pacheco, J., Guzmán, M., and Nieto, J., El graben de Querétaro, Querétaro, México. Observaciones de fallamiento activo, Geos, boletín de la Unión Geofísica Mexicana, 20, pp. 2-7 (2000).

3. Garduño, V.H., Arreygue, E., Israde, I., and Rodríguez, G.M., Efectos de las fallas asociadas a sobreexplotación de acuíferos y la presencia de fallas potencialmente sísmicas en Morelia, Michoacán, México, Revista Mexicana de Ciencias Geológicas, 18, 1, pp. 37-54 (2001).

4. Arroyo, M.G., Zemeño M.E. and Castañeda, J.A., El agrietamiento en Aguascalientes, causas y efectos, ISBN 968507390 2, edited by la Universidad Autonoma de Aguascalientes (2004).

5. Rojas, E., Arzate, J., and Arroyo, M.G., A method to predict the group fissuring and faulting causes by regional groundwater decline, Engineering Geology, 65, pp. 245-260 (2002).

6. Pacheco, J., Arzate, J., Rojas, E., Yutsis, V., Arroyo, M.G. and Ochoa, G., Delimitation of soil fissures zones due to ground subsidence using gravity data and finite element modelling in the Valley of Queretaro, Mexico, Engineering Geology, 84, pp. 143-160 (2006).

7. Jachens, C.R. and Holzer, L.T., Differential compaction mechanism for earth fissures near Casa Grande, Arizona, Geological Society of American Bulletin, 93, pp. 998-1012 (1982).

8. Avila, J.A. and Garduño, V.H., A GPR study of subsidence-creep-fault processes in Morelia, Michoacan, Mexico, Engineering Geology, 100, 1-2, pp. 69-81 (2008).

9. UNESCO, Guidebook to studies of land subsidence due to ground-water withdrawal, prepared for the International Hydrological Programme, Working Group 8.4, Joseph F. Poland Chairman and Editor (1984).

10. Borchers, J.W., Land subsidence case studies and current research, en Proceedings of the Dr. Joseph F. Poland Symposium on Land Subsidence, Association of Engineering Geologists, Special Publication, 8 (1998). 


\section{INVACO2}

11. USGS, Open-File Report 94-532, Prince, K.R., Galloway, D.L. and Leake, S.A. eds. U.S. Geological Survey Subsidence Interest Group Conference, Edwards Air Force Base, Antelope Valley, California (1995).

12. Dannemann, R.G.C., Manual de ingeniería de steel framing, Instituto Latinoamericano del Fierro y del Acero (ILAFA), pp. 147 (2005).

13. Sarmanho, A.M., and Moraes, R.C., Steel Framing: Arquitectura, Instituto Latinoamericano del Fierro y del Acero (ILAFA), ISBN: 978-956-8181-02-4, pp. 119 (2007).

14. AISI (American Iron and Steel Institute), AISI 2007 Edition: North American Specification for the Design of Cold-Formed Steel Structural Members and Commentary on the Specification (2007). 